\title{
A Survival Guide to Low-Resource Peer-Reviewed Creative Scholarship for Aspiring Clinician-Educators
}

\author{
Joel Yager ${ }^{1}$ (D) Alexis Ritvo ${ }^{1} \cdot$ Julie H. Wolfe ${ }^{1} \cdot$ Robert E. Feinstein $^{2}$ \\ Received: 11 July 2018 / Accepted: 7 August 2018 / Published online: 14 August 2018 \\ (C) Academic Psychiatry 2018
}

Substantial numbers of psychiatrists interested in academic careers do so as clinician-educators. For many, these roles carry at least some expectation for peer-reviewed "scholarly productivity," but exactly how this productivity is operationally defined varies considerably from department to department. Although on the basis of previous exposures most early career clinician-educators seem to feel at least somewhat competent as clinicians and educators, when it comes to meeting expectations for original scholarship, presenting at formal meetings, writing, and publishing, many feel intimidated and ill prepared and blindly muddle through. Furthermore, many early career clinician-educators find themselves in academically low-resource environments, having limited money, skills, and connections generally necessary to conduct or to participate in elaborate or involved scholarly projects. They may lack the time and wherewithal to write grant proposals requiring formal Institutional Review Board approval and funding submission. In this column, we review motivations, emphasize benefits, and highlight opportunities for lowresource peer-reviewed creative scholarship that might be particularly useful for this cohort of academically based professionals.

We define low-resource creative scholarship as an intellectual activity that generates new knowledge and requires little in the way of external funding, formal review of research proposals, or statistical or methodological expertise or consultation. Within this framework, some of the most important papers in the field, including many included on core reading lists for postgraduate programs are, in fact, the products of low-resource-dependent peer-reviewed creative scholarship (see for example [1, 2]). These creative scholarly activities

Joel Yager

joel.yager@ucdenver.edu

1 University of Colorado School of Medicine, Aurora, CO, USA

2 University of Texas, Austin, TX, USA are somewhat analogous to low-budget-independent films, whose artistic values and impacts can at times equal or exceed the value of bigger budget studio films.

Many psychiatric teaching settings do not afford clinicianeducators with prospects for readily attaching themselves to productive scholarly groups. In such settings, aspiring clinician-educators can adopt low-resource options. Even where higher-resource group possibilities exist, clinical educators will still want to consider opportunities that lowresource scholarship strategies can afford them - to take creative leads and to make productive use of the downtimes that often occur during the course of conducting higher-resource scholarship.

While preparing talks and posters for presentation might serve to initiate and focus creative scholarship, what follows presumes that most readers will want to achieve publication of peer-reviewed journal articles, preferred currencies of the realm for most promotions committees. With these goals in mind, we offer the following "survival guide," steps that can increase the likelihood of success in low-resource peerreviewed creative scholarship.

\section{Why Bother? Do a Motivational Analysis}

Clinician-educators need to first clarify their motivations. Be brutally honest as to why you are choosing to write in the first place. Maslow's hierarchy [3, 4] outlines many non-mutually exclusive needs potentially satisfied by getting published:

Safety and Security Practically speaking, publications can lead to (and may be required for) academic promotions, salary increases, and new job possibilities.

Affiliation-Belongingness Scholarly activities afford opportunities to play and collaborate with stimulating colleagues at local, national, and at times international levels. Focusing on specific fields of study can help consolidate your academic 
interests and professional identity, provides validating external acknowledgements, and fosters your membership in recognized communities and networks of scholars-your tribes.

Esteem-Self-Esteem Scholarly accomplishments bolster your self-esteem and your reputation and status among peers, friends, and family.

Self-Actualization In our view, the most important reasons for conducting original scholarship are honoring and channeling curiosity, sparking creative thoughts, stimulating deep learning, developing new knowledge, and seeing one's competent writing achieving publication. These efforts can inject your career - and life as a whole - with ongoing generativity, purpose, meaning, amusement, pleasures of concrete accomplishment, and altruistic satisfactions, all of which can help avert burnout.

\section{What, Exactly, Should You Take on? Conduct a "SWOT" Analysis}

Understand your personal Strengths and Weaknesses as well as environmental $O$ pportunities and $T$ hreats (acronymically referred to as a "SWOT" analysis) as they impact your abilities to engage in publication-oriented scholarly activities.

Personal What is the status of your initial scholarly skillset? How curious are you? How well can you spot limitations, gaps, and contradictions in the knowledge bases and theories which inform current psychiatric practices? Assess your capacities to search and synthesize literature, identify gaps in information, create original ideas, identify new directions, develop quality and safety projects, gather information, and then present, write, and ultimately get published. Almost all aspirants start out with extremely limited repertoires, but these competencies can be readily learned.

Environmental What resources can you access with respect to discretionary time, support (e.g., administrative staff, money), mentoring, and collaboration, locally and through connections elsewhere? How much of your personal discretionary time, energy, and money are you willing to invest in your scholarly efforts (considering them to be long-term career investments)? Generally available even in low-resource situations, PubMed, JSTOR, Survey Monkey, and other Internet-based information, communication, and data acquisition services constitute easily accessed assets.

What, exactly, are your department's and school's expectations regarding publishing for continued employment and promotion? What are clinician-educators expected to produce by way of first- or co-authorships in peer-reviewed journal articles, book chapters, and other venues? Mentors, chairs, members of promotions committees, and faculty ahead of you on the academic ladder should provide candid appraisal about requirements for maintaining and advancing clinicianeducator research careers.

\section{Find Mentors}

Seek out and surround yourself with general and technical mentors you can call upon for help with overall career and work-life balance issues and/or specific skills - everything short of personal psychotherapy. Good mentors advise, guide, prod, reality check, connect, open doors, point you toward opportunities and resources, look over your shoulder, have you look over their shoulders, keep you honest and accountable, steer you away from ill-advised choices, remind you of deadlines and timelines, collaborate at times, listen when you are having difficulties, help you know what to look for and how to ask for it, and do not take advantage of you. If suitable mentors are not available locally, look to national organizations where mentor-mentee relationship-building is heavily promoted.

\section{Collaborate}

Collaborating with others locally or via regional or national professional organizations who share your interests can lead to productive, mutually beneficial scholarly connections and lifelong, rewarding friendships. Collaborators can keep you motivated, facilitate productive schedules, and hold you accountable to produce on deadline even if you might otherwise procrastinate. Most collaborators appreciate others' willingness to help with demanding projects, might eagerly involve you in their work, and are usually more than happy to share authorship. Many also enjoy mentoring. Expanding collaborations with individuals in other local departments or in other centers may turn single individuals' interests into multi-scholar, multi-disciplinary, and even multi-site projects. Finally, since collaborative scholarship is a form of adult play, be highly selective about your playmates. Pick people with whom you enjoy spending time and whom you can trust. Avoid getting entangled with questionable, unreliable, incompetent, or quirky characters who might take advantage of you or who might not complete their portions of the work.

\section{Map Out Your Scholarly Areas}

Although some people know precisely what they would like to study and write about, many others feel lost. Review your professional passions. What clinical, educational, administrative, and/or systems-based interests, questions, and problems 
inspired your career in the first place or stare you in the face on a daily basis? When possible, align your writing with your ongoing work, giving free reign to your curiosity and private irritations. In clinical settings, work-related quality and safety projects can be relatively easy to accomplish. When collaboratively conducted, teams might provide mentors and technical assistance (http://medicine.ucsf.edu/safety/resources/ journals.html). Even if such scholarly engagement does not yield practical solutions, contending with these issues via reading, research, and writing might reduce frustration via active modes of coping and, perhaps, offer some satisfactions through publishing.

\section{What Types of Scholarly Writing Projects Are Good Places to Begin?}

For practice and desensitization, new faculty with zero publishing experience might start by developing a poster for a national meeting or submitting a case report, alone or with collaboration. Meeting posters require careful attention to organization, effectively presenting your thinking, and limited text. And, as one of our mentors advocated, "If it is worth presenting, it is worth writing up." Case reports, as solo efforts or collaborative vehicles, offer scholarly worth by identifying novel or unusual presentations and by suggesting innovative hypotheses or directions.

Beyond these initial efforts, subsequent efforts at peerreviewed publication will depend on topics, data, ideas, and the scope of work: case series, thought-piece essays and commentaries, reviews, descriptions and evaluations of model curricula, quality improvement projects, up to and including more formal research or systematic review studies, and even complete books.

Prepare to Write Up Your Manuscripts Several pointers merit special emphasis. Before you start any work, think specifically about your intended audiences and likely publication venues.

Pick Likely Journals When starting a trip, know your destination. Strongly consider your most realistic options. Table 1 lists general, psychiatric, medical education, and quality improvement journals that invite various types of low-resource scholarship.

In picking journal options, are you writing on a topic suitable for a broad medical audience or a more narrowly specialized one? Cross-discipline, intra-discipline, or subsubspecialty clinical, medical education administrative or quality care-focused journals? Familiarize yourself with a wide range of potential journals via google (e.g., http:// www.scimagojr.com/journalrank.php?category $=2738$ listed 525 psychiatric journals and their impact factors). We suspect that this number will continue to grow. Be certain that journals to which you submit are indexed in important databases such as MEDLINE by the National Library of Medicine and that you studiously avoid the proliferating numbers of scam, fake journals. Cabell's Directory of Publishing Opportunities, available through University library services, provides information about journals' acceptance and rejection rates (rejection rates for better journals are ordinarily quite high, and even mid-level journals pride themselves on high rejection rates, signifying status).

Before writing a word, learn the article formats and specifications for the journals to which you will first submit. Consider each journal's detailed instruction for authors (on the journal's website) and adhere to instructions regarding formats, topics, methods, word count, abstracts, article sections, references, and any other particulars. Before formally submitting your manuscript, consider emailing the editor a brief description of the article (e.g., title and abstract) or even the entire manuscript to ask whether formal submission is reasonable. Several journals specifically request presubmission inquiries. If your manuscript seems entirely misaligned in substance or form with a particular journal's mission, you will save everyone time and effort by not submitting there.

Think Title Realize that most readers decide whether or not to read an article solely on the basis of the title. Does the title entice potential readers to read further? If a reader retained only one line of information from your article, what would you want the reader to remember? If at all possible, the title should include that nugget.

Write the Abstract, Especially a Structured Abstract If you can write a sharp abstract clearly summarizing your important points, you are probably ready to write the paper; if you are not clear on what to put into the abstract, you are not ready to write. After titles, most readers will actually read abstracts, and most stop there. Internists report reading only the abstracts for about two-thirds of articles they peruse [5].

Write the Paper Settling down to actual writing, several options exist for getting started. Some writing coaches suggest beginning with a formal outline and topic sentences to open each paragraph followed by lists of points to be made in subsequent sentences. Yet another strategy employs mindmapping [6], starting with large poster boards and colored pens, jotting down and drawing all thoughts associated with the article, adding others as they come to mind, and then connecting scattered words and phrases that hang together conceptually with circles and lines, all before generating an outline. Outlines with specific topic sentences help ideas sort themselves out. 
Table 1 Types of low-resource publications accepted by psychiatrically salient general and specialty journals

Journal name and URL for associated guidance or instructions for authors

Types of publications accepted

Academic Medicine https:/journals.lww.com/academicmedicine/Pages/InformationforAuthors.aspx

d, e, h, i, k, m

Academic Psychiatry https://www.springer.com/medicine/psychiatry/journal/40596?detailsPage=societies

$\mathrm{a}, \mathrm{d}, \mathrm{e}, \mathrm{f}, \mathrm{h}, \mathrm{i}, \mathrm{j}, \mathrm{k}, \mathrm{l}, \mathrm{m}, \mathrm{n}$

Acta Psychiatrica Scandinavica https:/onlinelibrary.wiley.com/page/journal/16000447/homepage/forauthors.html

$\mathrm{i}, \mathrm{j}$

Addiction http://www.addictionjournal.org/pages/authors\#types

d, f, i, o

Advances in Health Sciences Education: Theory and Practice https://www.springer.com/education+

$\mathrm{d}, \mathrm{h}, \mathrm{j}$

\&+language/journal/10459

Alcoholism: Clinical \& Experimental Research https://onlinelibrary.wiley.

com/page/journal/15300277/homepage/forauthors.html

American Journal of Geriatric Psychiatry http://www.editorialmanager.com/jgp/default.aspx

American Journal of Medical Quality https://us.sagepub.

com/en-us/nam/american-journal-of-medical-quality/journal201749\#submission-guidelines

American Journal of Psychiatry https://ajp.psychiatryonline.org/ajp_ifora

American Journal of Psychotherapy https://psychotherapy.psychiatryonline.org/psychotherapy_ifora

$\mathrm{c}, \mathrm{j}$

c, e, i, j

d

American Journal on Addiction https://onlinelibrary.wiley.com/page/journal/15210391/homepage/forauthors.html

Annals of Clinical Psychiatry https://www.aacp.com/instructions-for-authors/

Biological Psychiatry https://www.elsevier.com/journals/biological-psychiatry/0006-3223/guide-for-authors

Bipolar Disorders https://onlinelibrary.wiley.com/page/journal/13995618/homepage/forauthors.html

BMC Journal of Medical Case Reports (Open)* https://jmedicalcasereports.biomedcentral.com/submission-guidelines

BMC Medical Education https://bmcmededuc.biomedcentral.com/submission-guidelines

British Journal of Psychiatry Advances https://www.cambridge. org/core/journals/bjpsych-advances/information/instructions-contributors

British Medical Journal https:/www.bmj.com/about-bmj/resources-authors/article-types

BMJ Case Reports http://casereports.bmj.com/site/about/guidelines.xhtml

BMJ Quality and Safety http://qualitysafety.bmj.com/pages/authors/

Bulletin of the Menninger Clinic https://www.guilford.com/periodicals/jnmeinst.pdf

Current Psychiatry https://www.mdedge.com/psychiatry/page/submission-guidelines-0

Depression and Anxiety https://onlinelibrary.wiley.com/page/journal/15206394/homepage/forauthors.html\#_3._ MANUSCRIPT CATEGORIES

Drug Alcohol Dependence https://www.elsevier.com/journals/drug-and-alcohol-dependence/0376-8716?generatepdf=true

Education for Health http://www.educationforhealth.net/contributors.asp

Frontiers in Psychiatry (Open) * https://www.frontiersin.org/journals/psychiatry\#author-guidelines

General Hospital Psychiatry https://www.elsevier.com/journals/general-hospital-psychiatry/0163-8343/guide-for-authors

Harvard Review of Psychiatry https://journals.lww.com/hrpjournal/Documents/HRP\%20Instructions\%20for\%20Authors\% 20July\%202017.pdf

International Journal of Eating Disorders https:/onlinelibrary.wiley.com/page/journal/1098108x/homepage/forauthors.html

International Journal for Quality in Health Care https://academic.oup.com/intqhe/pages/instructions_to_authors

Joint Commission Journal on Quality and Patient Safety https://www.jointcommissionjournal.com/content/authorinfo\# idp 1257424

JAMA https://jamanetwork.com/journals/jama/pages/instructions-for-authors

JAMA Psychiatry https://jamanetwork.com/journals/jamapsychiatry/pages/instructions-for-authors

Journal of Child and Adolescent Psychiatry https://www.pulsus.

com/journal-child-adolescent-psychiatry/instructions-to-authors.html

Journal of Clinical Psychiatry http://www.psychiatrist.com/pages/authors.aspx

Journal of Clinical Psychopharmacology http://edmgr.ovid.com/jcp/accounts/ifauth.htm

Journal of Continuing Education in the Health Professions http://edmgr.ovid.com/jcehp/accounts/ifauth.htm

Journal of ECT http://edmgr.ovid.com/ject/accounts/ifauth.htm

Journal of General Internal Medicine https://jgimed.org/authors/JGIM\%20Instructions\%20for\%20Authors.pdf

Journal of Graduate Medical Education http://www.jgme.org/page/author_instructions?code=gmed-site\#types

Journal of Health Care for the Poor and Underserved https://www.press.jhu.

edu/journals/journal-health-care-poor-and-underserved/author-guidelines

Journal of Nervous and Mental Diseases http://edmgr.ovid.com/jnmd/accounts/ifauth.htm

$\mathrm{e}, \mathrm{i}, \mathrm{k}$,

$\mathrm{d}, \mathrm{j}, \mathrm{o}$

$\mathrm{c}, \mathrm{i}, \mathrm{j}$

$\mathrm{c}, \mathrm{j}, \mathrm{i}$

d (usually invited)

d, i, j, e

c

c, d

$\mathrm{d}, \mathrm{e}, \mathrm{j}, \mathrm{m}$

b, d, e, o

c

d, f, h, i, j

$\mathrm{c}$

$\mathrm{d}, \mathrm{e}, \mathrm{m}$

j

$\mathrm{i}, \mathrm{j}$

c, d, e, f, g, h, i, 1, m, o

c, d, e, f, g, j

$\mathrm{f}, \mathrm{i}, \mathrm{j}$

$\mathrm{c}, \mathrm{d}, \mathrm{e}, \mathrm{j}, \mathrm{o}$

$c, d, f, g, h, j$

$\mathrm{c}, \mathrm{d}, \mathrm{j}$

$\mathrm{d}, \mathrm{f}, \mathrm{h}, \mathrm{j}, \mathrm{m}$

c, d, e, f, j, o

d, e, f, g, h, I, j, o

c, d, e, f, g, h, i, j

$\mathrm{c}, \mathrm{i}$

i

d, f, g, h, j, o

c, d, i, j,o

c, d, e, f, j, o

d, f, h, i, j

c, d, e, f, g, j, m

f

c, d, f, i, j, o 
Table 1 (continued)

Journal name and URL for associated guidance or instructions for authors

Types of publications accepted

Journal of Neuropsychiatry and Clinical Neurosciences https://neuro.psychiatryonline.org/neuro_ifora

Journal of Psychiatric Practice http://www.editorialmanager.com/pra/default.aspx

$c, d, e, f, g, i, j, k$

Journal of Psychiatric Research https://www.elsevier. com/journals/journal-of-psychiatric-research/0022-3956/guide-for-authors

Journal of Studies on Alcohol and Drugs https://www.jsad.com/page/instructions

Journal of the American Academy of Child and Adolescent Psychiatry https://www.jaacap.org/content/authorinfo

Lancet http://www.thelancet.com/pb/assets/raw/Lancet/authors/lancet-information-for-authors.pdf

Lancet Psychiatry https:/www.elsevier.com/journals/the-lancet-psychiatry/2215-0366/guide-for-authors

MedEdPortal https://www.mededportal.org/authors/

Medical Education https://onlinelibrary.wiley.com/page/journal/13652923/homepage/forauthors.html

Medical Teacher http://www.medicalteacher.org/medteach_wip/pages/authinfo.htm

Molecular Psychiatry http://media.nature.com/full/nature-assets/mp/mp_gta.pdf

New England Journal of Medicine https:/www.nejm.org/author-center/article-types

Psychiatric Services https://ps.psychiatryonline.org/doi/full/10.1176/appi.ps.51.2.185

Psychiatry: Interpersonal and Biological Processes http://www.wspdc.org/pdf/InstructionsAuthors.pdf

Psychological Medicine https://www.cambridge.

org/core/journals/psychological-medicine/information/instructions-contributors

Psychopharmacology https://www.springer.com/authors/manuscript+guidelines? SGWID = 0-40,162-6-1,529,944-0

Psychosomatic Medicine https://journals.lww.com/psychosomaticmedicine/pages/instructionsforauthors.aspx

Psychosomatics https://journals.lww.com/psychosomaticmedicine/pages/instructionsforauthors.aspx

Psychotherapy and Psychosomatics https://www.karger.com/Journal/Guidelines/223864

Psychotherapy http://www.apa.org/pubs/journals/pst/resources.aspx

Quality Management in Health Care http://edmgr.ovid.com/qmh/accounts/ifauth.htm

Teaching and Learning in Medicine https://mc.manuscriptcentral.com/societyimages/htlm/Instructions\%20for\% 20Contributors_February\%202016.pdf

The Clinical Teacher https://mc.manuscriptcentral.com/societyimages/tct/Author\%20Guidelines.pdf

World Journal of Psychiatry https://www.wjgnet.com/bpg/gerinfo/204 c, d, e, f, m, o

$\mathrm{f}, \mathrm{i}, \mathrm{j}$

$\mathrm{f}, \mathrm{i}, \mathrm{j}$

c, d, e, i, j, k, l, m, n, o

$\mathrm{c}, \mathrm{d}, \mathrm{g}$

d

$\mathrm{e}$

d, e, f, i, j, m

$\mathrm{d}, \mathrm{f}, \mathrm{i}, \mathrm{m}$

d

b, c, d

c, d

c, d, e, j, o

i

$\mathrm{d}, \mathrm{j}, \mathrm{l}$

i

c, f, i, j,

b, d, h, i

b, d, j

b, d, f, j

$\mathrm{e}$

e, f, j, h, m

c, d, f, i, j

a, annotated bibliography; b, case management; c, case reports (including adverse reaction reports), case series; d, commentary, perspectives, missions, personal views; e, educational reports (including educational case reports, innovations, observations, columns); f, empirical report (generally requires descriptive statistics at minimum; may be brief report); g, hypotheses; h, innovation; i, letter to the editor, correspondence; j, narrative reviews (i.e., not necessarily systematic reviews); $\mathrm{k}$, poetry, first-person account essays, and other creative work; 1, position statement (represents professional organization); m, practical advice (usually column, e.g., "Down to Earth," "Tips," "Skills," "Technological Application"); n, task force reports (represents professional organization; o, miscellaneous additional low-resource formats

* "Open" signifies an "open access" journal, using business models that allow authors to retain copyright and distribution rights to their research in return for fees paid to the publisher by the authors or their institutions. Many current journals offer "hybrid" options, ranging from full open access to traditional publishing models in which copyrights are retained by publishers and authors pay no publication fees

Introductions should be brief, stating what problems are being addressed, gaps and conflicts in the literature, and the paper's aims and scope. The introductory literature review should be concise, selective, and current; unless you are doing a formal systematic review, you are not expected to review the world's literature. However, in addition to citing the most prominent authors whose works matter, be certain to include any you or your colleagues think the editor might call upon to serve as blind reviewers, especially citing articles published in the journal to which you are submitting.

Tables can help organize the main points and also help structure your writing.
Some journals limit the number of references they publish for certain types of articles, for example, no more than 20 for case reports. If so, budget accordingly.

Finally, Prune Ruthlessly One of our senior mentors routinely advised new authors, who tend to be verbose and redundant, to aim at deleting roughly two out of three words from their initial drafts. The trick is deciding which words to drop. Several days' distance from the initial draft often increases editorial objectivity. Be especially wary of overstuffed literature reviews, meandering off-topic discussions, soap-box rants, and theoretical hobby-horses not crucially pertinent to 
the topics at hand. Good writing favors action verbs and avoids passive grammatical constructions, unnecessary adverbs, adjectives, and articles, and convoluted sentences.

\section{Before You Submit, Ask Colleagues to Review and Comment}

To respect colleagues' time, provide reasonably close-to-final drafts, and let them know that you want honest, detailed, even nitpicking feedback, not just compliments. Do your ideas make sense? Does the paper seem reasonably well organized? How about the writing style and grammar? Better to learn about problems from your friends than from reviewers. Try minimizing your personal hypersensitivities to critical feedback, be quick to fix identified difficulties, and be prepared to reciprocate.

\section{Discussion}

Even clinician-educators whose local environments are low in resources should now be able to access presentations, workshops, courses, and seminars on clinical research and medical writing online, at national meetings, and through excellent publications [7-12]. We strongly urge aspirants to avail themselves of these resources.

Scholarly activities and achieving publication should be fun, significantly activate the clinician-educator's reward centers, and further knowledge. Personal benefits include honoring, promoting and sustaining ongoing curiosity and generativity, deep learning, development of special expertise, and self-expression, as well as reducing burnout and fostering concrete accomplishment. Professional benefits include esteem, recognition, and contributions to promotion.

In one of our writing seminars, a young psychiatric resident, extremely intimidated and awed by the idea of ever being "published," was thrilled beyond expectations when her submitted case report was accepted by a major psychiatric journal. She proudly sent her mother a framed copy of the published article to hang in the family kitchen. She described publishing her first paper as less arduous than having her first child and thought publishing would be much less fearful and more fun on subsequent occasions. And, she said, "Writing papers is really a much more productive way to spend time than playing golf, and, who knows, you might actually help someone."

\section{Compliance with Ethical Standards}

Disclosures On behalf of all authors, the corresponding author states that there is no conflict of interest.

\section{References}

1. Braslow K. Best articles for psychiatry residents. Simple and Practical Mental Health Posted February 2, 2018 https:// luminello.com/best-articles-for-psychiatry-residents/. Searched July 27, 2018.

2. Academy of Consultation-Liaison Psychiatry. Reading/reference list for psychiatry residents rotating in C-L psychiatry Updated June 2017. https://www.clpsychiatry.org/wp-content/uploads/ resident-readinglist.pdf. Searched July 27, 2018.

3. Maslow AH. Motivation and personality. 2nd ed. New York: Harper \& Row; 1970.

4. Kenrick DT, Griskevicius V, Neuberg SL, Schaller M. Renovating the pyramid of needs: contemporary extensions built upon ancient foundations. Perspect Psychol Sci. 2010 May;5(3):292-314.

5. Saint S, Christakis DA, Saha S, Elmore JG, Welsh DE, Baker P, et al. Journal reading habits of internists. J Gen Intern Med. 2000;15(12):881-4.

6. Buzan T, Griffiths C, Harrison J. Modern mind mapping for smarter thinking. Proactive Press, 2012.

7. Brakoulias V, Macfarlane MD, Looi JC. The rites of writing papers: steps to successful publishing for psychiatrists. Australas Psychiatry. 2015 Feb;23(1):32-6.

8. Coverdale JH, Roberts LW, Balon R, Beresin EV. Writing for academia: getting your research into print: AMEE Guide No. 74. Med Teach. 2013;35(2):e926-34.

9. Weiss LR, Hilty DM (editors). Handbook of career development in academic psychiatry and behavorial sciences, Second Edition. Arlington, Virginia, American Psychiatric Press, Inc. 2017.

10. Weiss LR. The clinician educator guidebook: steps and strategies for advancing your career. New York: Springer; 2016.

11. Hulley SB, Cummings SR, Browner WS, Grady DG, Newman TB. Designing clinical research. 4th ed. Philadelphia: Williams and Wilkins/Wolters Kluwer; 2013.

12. UCSF Designing clinical research web resources. http://www.dcr4.net/. 